\title{
Correction to: Secure convergence of artificial intelligence and internet of things for cryptographic cipher-a decision support system
}

\author{
Lin Shi ${ }^{1} \cdot$ Shah Nazir ${ }^{2}$ (D) Liquan Chen ${ }^{3} \cdot$ Rui Zhu ${ }^{3}$ \\ Published online: 10 May 2021 \\ C Springer Science+Business Media, LLC, part of Springer Nature 2021
}

\section{Correction to: Multimedia Tools and Applications (2020) https://doi.org/10.1007/s11042-020-10489-1}

In the original publication of this article, Lin Shi was left out as one of the corresponding authors. Both Lin Shi and Shah Nazir are corresponding authors. The original article has been corrected.

Publisher's note Springer Nature remains neutral with regard to jurisdictional claims in published maps and institutional affiliations.

The online version of the original article can be found at https://doi.org/10.1007/s11042-020-10489-1

\section{Lin Shi}

shiling717@nuaa.edu.cn

$\triangle$ Shah Nazir

snshahnzr@gmail.com

1 College of Economics and Management, Nanjing University of Aeronautics and Astronautics, Nanjing Jiangsu 211106 Jiangsu, China

2 Department of Computer Science, University of Swabi, Ambar, Pakistan

3 School of Cyber Science and Engineering, Southeast University, Nanjing Jiangsu 210096 Jiangsu, China 